\title{
Analysis and Comparison of Different Dewatering Methods On Salt Quality
}

\author{
Nizar Amir ${ }^{*}$, Makhfud Efendy ${ }^{2}$, Rachmad Hidayat ${ }^{3}$ and Misri Gozan ${ }^{4}$ \\ ${ }^{1}$ Department of Mechanical Engineering, University of Trunojoyo Madura, 69162, Indonesia \\ ${ }^{2}$ Department of Marine Science, University of Trunojoyo Madura, 69162, Indonesia \\ ${ }^{3}$ Department of Industrial Engineering, University of Trunojoyo Madura, 69162, Indonesia \\ ${ }^{4}$ Chemical Engineering Department, Universitas Indonesia, Kampus UI Depok, 16424, Indonesia
}

\begin{abstract}
The salt quality was studied by dewatering methods such as centrifugal hydro extraction, fixed bed dryer, and rotary drum dryer. The effect of different salt particle sizes was also analyzed. The centrifugal hydro extractor is found to be effective when reducing the high-water content of salt and suitable for reducing water content after the salt wash stage. Fixed bed dryers produce lower water content than rotary drum dryers. A water content lower than $1 \%$ can be achieved using fixed bed dryers. Finally, all dewatering methods such as centrifugal hydro extractors, fixed bed dryers, and rotary bed dryers are suitable for salt production methods. Reduced salt particle size from 30 to 60 mesh also improved the drying performance.
\end{abstract}

Keyword: Salt Quality, Dewatering Methods, Centrifugal Hydro Extraction

\section{Introduction}

Madura Island has a massive number of solar salt ponds. It is spread over in all districts in Madura Island and has developed since the Dutch occupation era [1]. Farmer in Madura produces salt with traditional methods, and they highly depend on the weather condition[2], [3]. The produced salt is packed in blue sacks then stored at the warehouse around the solar salt pond, as shown in Figure 1 . The crude solar salt is processed in the factory to improve the quality and consumed by industry. Several chemical and engineering methods have been proposed to produce better salt quality [4]-[8]. The dewatering method was used to reduce particle water content by centrifugation and drying [9]. Commonly in industry, the crude solar salt is ground then washed with saturated brine water in the initial stage. A Centrifugal hydroextractor is used to reduce the water content after the washing stage. The drying process is used before salt is ready to pack. The drying method has been widely used in industry to improve the quality of the product [10]-[13]. In addition, salt drying is a critical method in the salt industry to improve salt quality [14]. To reduce the cost of production, necessary to adapt the effective salt drying technology. However, drying is one of the most energy-consuming in industries and has its advantages and disadvantages [15]-[17]. The selection of drying technology is essential to produce better salt quality at an economical price. The objective of this work was to analyze and comparison of different dewatering methods on salt quality. The dewatering methods such as centrifugal hydroextractor, fixed bed dryer, and rotary drum dryer were examined.

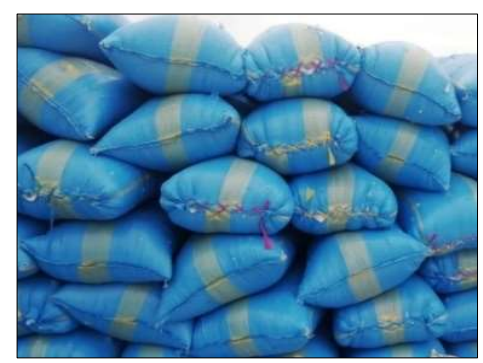

(a)

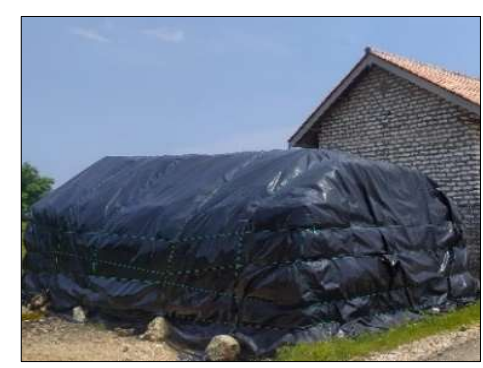

(b)

Fig.1. Traditional salt (a) packed in a blue sack, (b) storage near the solar salt pond

\footnotetext{
*Corresponding author : nizar.amir@trunojoyo.ac.id
} 
The effect of different salt particle sizes was also compared. In addition, the quality of salt will be measured on water content percent. This study result was significant as guidance for developing a salt processing industry, mainly producing dried salt products required by industry.

\section{Materials and methods}

\subsection{Salt materials}

Crude solar salt was supplied by the traditional solar salt pond and taken from the exact location to ensure the same quality. The crude solar salt was milled to a particle size 30 and 60 mesh by micro mill equipment.

\subsection{Dewatering Methods}

Centrifugal hydro extractor procedure: The salt sample was washed in saturated brine for 2 minutes. After the salt wash process, salt drained until $30 \%$ water content and then put on 50 microns white fine transparent wrapping cloth before dewatering process. The dewatering process by centrifugal hydro extractor was conducted at different dewatering times $(10,15,20,25$, 30 minutes). The rotational speed was maintained at 750 rpm.

Fixed bed dryer and rotary drum drying procedure: The salt sample was first washed in saturated brine for 2 minutes, and it drained by the centrifugal hydro extractor to reduce the water content until $11 \%$, then it was dried at $70^{\circ} \mathrm{C}$ for 5 minutes to ensure the sample has $10 \%$ water content uniformity. The dried crude solar salt samples were stored on a polyethylene storage box before the drying process. The dewatering process by fixed bed hot air and rotary drum drying was conducted at different dewatering times $(10,15,20,25,30$ minutes). For the rotary drum dryer, the different dewatering times were conducted by varying rotational $\mathrm{rpm}$. The drying temperature was fixed at $80^{\circ} \mathrm{C}$ for both dryers. The fixed bed dryer using no head cover, so the moisture is quickly released into the environment.

\subsection{Water Contents}

The water content of salt samples was determined by oven drying to a constant mass at $105^{\circ} \mathrm{C}$ for 6 hours [14].

\section{Results and discussion}

\subsection{Centrifugal hydro extractor}

Centrifugal hydroextractor was critical equipment to reduce the water content after the salt wash process. With increasing dewatering time from 10 to 30 minutes, the water content reduced slightly for all particle sizes, as shown in Figure 2. In addition, a centrifugal hydro extractor has a high potential to reduce high water content in a short time. The water content reduced from $30 \%$ to $10,5 \%$ and 9,89 in 10 minutes for 30 mesh and 60 mesh salt particle size, respectively. However, this equipment does not effectively reduce small water content, after $10 \%$ water content is achieved, the slightly reduced water content is gained. Increase the dewatering time from 10 to 30 minutes only $1,55 \%$ and $1,78 \%$ water content reduced for 30 mesh and 60 mesh, respectively. Reduced particle size improves the dewatering process. For example, in 10 minutes of dewatering time, 60 mesh salt particle size has lower water content than 30 mesh, as shown in Figure 2

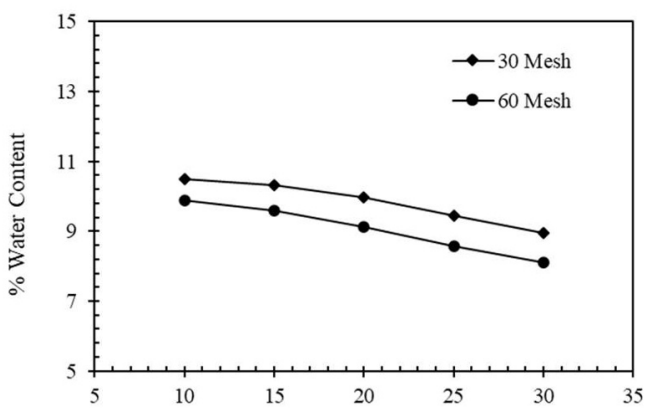

Fig.2. Effect of dewateringritimnienon water content using centrifugal hydroextractor

\subsection{Fixed Bed Dryers}

The drying process was a vital process for salt industry application to produce dry salt crystals. Figure 3. shows that increased the dewatering time will reduce the water content. The water content reduced from $8,43 \%$ to $1,18 \%$ when the dewatering time was increased from 10 to 30 minutes for 30 mesh particle size.

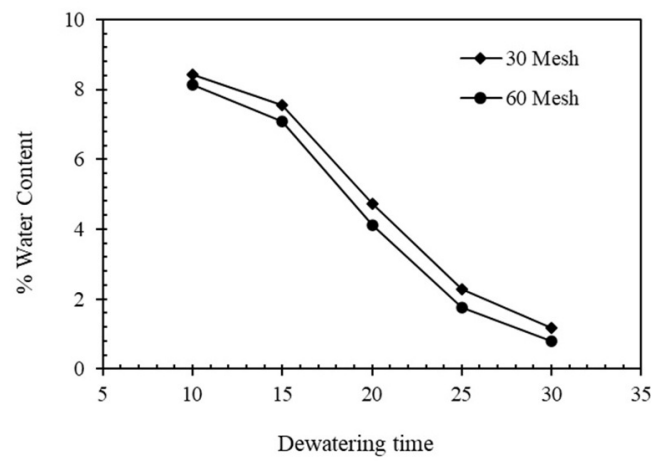

Fig.3. Effect of dewatering time on water content using fixed bed dryer

The lowest water content was obtained in 60 mesh particle size, indicating that reducing particle size improves the drying process. This was due to smaller particle sizes provide a larger surface area then it improves the drying process [18], [19]. In addition, reduced particle size also breaks the porosity of the salt crystal then releases the water content inside the salt crystal. Drying salt with a fixed bed dryer is suitable for producing high-quality dry salt crystals accepted by the industry. The lowest water content obtained by using a fixed bed dryer was $0,8 \%$, as shown in Figure 3. 


\subsection{Rotary Drum Dryers}

A rotary drum dryer is commonly used in the salt industry to reduce salt the water content of salt particles [20]. Figure 4. shows that the rotary drum drying removed the water content with increasing temperature. rotary drum dryer, respectively. Using a fixed bed dryer provides a higher drying rate and thus leads to a reduced high amount of water content [17]. This is why the water content of the fixed bed dryer was lower than the rotary drum dryer.

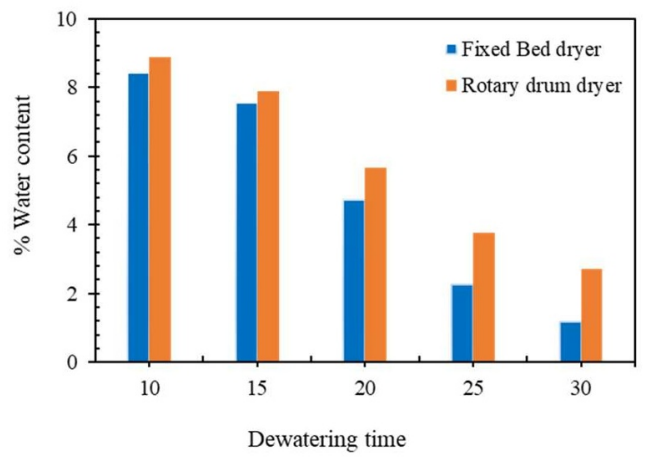

(a)

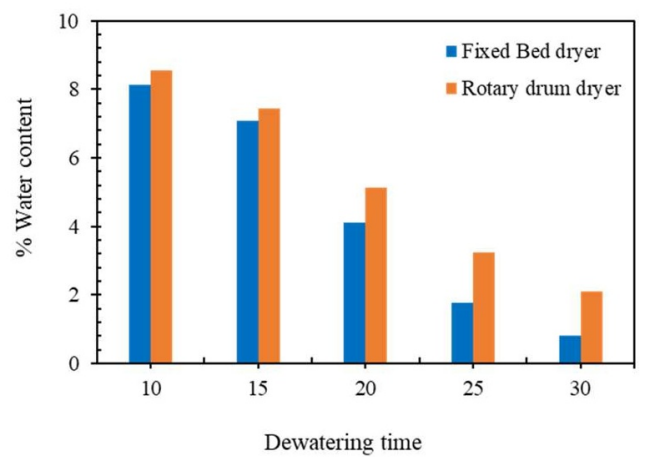

(b)

Figure 5. Effect of dewatering time on water content from different dewatering methods for (a) 30 mesh, (b) 60 mesh particle size

The water content reduced from $8,89 \%$ to $2,72 \%$ when the dewatering time was increased from 10 to 30 minutes for 30 mesh particle size. Like a fixed bed dryer, the water content decreased significantly after 15 minutes of dewatering time and decreased slowly after 25 minutes. It also indicates that the dewatering time required to reach the lowest water content was 30 minutes, as shown in Figure 4.

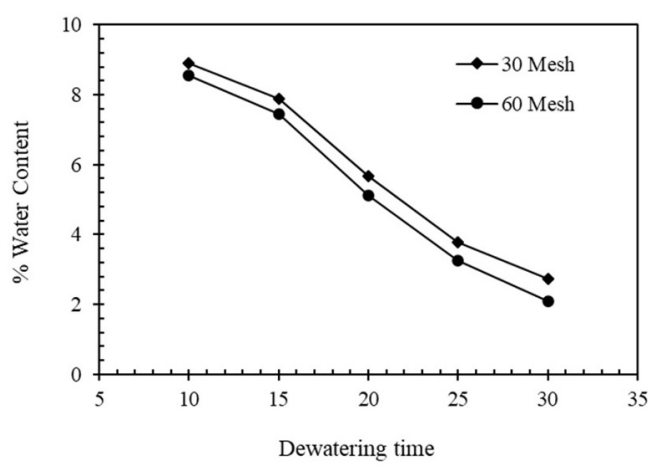

Fig.4. Effect of dewatering time on water content using rotary drum dryer

\subsection{Comparison dewatering methods}

Water content is considered one of the critical requirements for the salt industry. Fig. 5 gives results of reducing water content with increasing dewatering time in fixed bed and rotary drum dryers. It has been shown that 30 minutes of dewatering time is needed to obtain the water content below $2 \%$ for both dewatering methods. The water content result of using a fixed bed dryer was lower than the rotary drum dryer. At 30 minutes with 30 mesh particle size, the water content was $1,18 \%$ and $2,72 \%$ obtained by the fixed bed and
Reduced particle size also improved the dewatering performances. For example, using a fixed bed dryer in 30 minutes provides $1,18 \%$ and $0,8 \%$ water content for 30 and 60 mesh, respectively. The lowest water content was obtained for the fixed bed and rotary drum dryer in 30 minutes were $0,8 \%$ and $2,1 \%$, respectively.

\section{Conclusions}

The salt property, such as water content, is fundamental in industry and is significantly impacted by dewatering methods. The dewatering methods such as centrifugal hydroextractor, fixed bed dryer, and rotary drum dryer have been investigated. Based on this study, several dewatering methods have different functions and must be correctly chosen in the salt industry. Centrifugal hydroextractor is suitable for utilization after the salt wash process due to quickly reducing a high amount of water content. However, this method does not give any advantages to reduce small water content. Among the drying methods, a fixed bed dryer led to the lowest water content. A fixed bed dryer is an appropriate drying method for industrial-scale because it produces salt with water content lower than $1 \%$. Reduce the particle size also improve the performance of the drying method.

\section{References}

[1] M. Z. Mahasin, Y. Rochwulaningsih, and S. T. Sulistiyono, "Coastal Ecosystem as Salt Production Centre in Indonesia," E3S Web Conf., vol. 202, (2020), doi: 10.1051/e3sconf/202020207042.

[2] M. Gozan et al., "High-Productivity Traditional Bali Palung Salt Method for Small Production Fields," vol. 48, no. 6, (2021). 
[3] Y. Rochwulaningsih et al., "Traditional knowledge system in palung salt-making in Bali Island," J. Ethn. Foods, vol. 6, no. 1, pp. 4-10, (2019), doi: 10.1186/s42779-019-0018-2.

[4] M. M. Abu-Khader, "Viable engineering options to enhance the $\mathrm{NaCl}$ quality from the Dead Sea in Jordan," J. Clean. Prod., vol. 14, no. 1, pp. 80-86, (2006), doi: 10.1016/j.jclepro.2004.11.005.

[5] Z. Li, R. Li, X. Liu, C. Zhao, and Y. Tian, "Application and Product Standard of Purified Crystalline Salt from Desulfurization Wastewater of Thermal Power Plant," E3S Web Conf., vol. 136, (2019), doi: 10.1051/e3sconf/201913606019.

[6] K. G. Nayar et al., "Cost and energy requirements of hybrid RO and ED brine concentration systems for salt production," Desalination, vol. 456, no. November 2018, pp. 97-120, (2019), doi: 10.1016/j.desal.2018.11.018.

[7] J. Zhao, H. Cheng, X. Wang, W. Cheng, and F. Cheng, "Experimental investigation and cost assessment of the salt production by solar assisted evaporation of saturated brine," Chinese J. Chem. Eng., vol. 26, no. 4, pp. 701707, (2018), doi: 10.1016/j.cjche.2017.08.016.

[8] M. Ahmed et al., "Feasibility of salt production from inland RO desalination plant reject brine: A case study," Desalination, vol. 158, no. 1-3, pp. 109-117, (2003), doi: 10.1016/S00119164(03)00441-7.

[9] O. Moiambo and F. Ferreira, "Modelling Faecal Sludge Dewatering Processes in Drying Beds Based on the Results from Tete, Mozambique," (2021).

[10] M. U. Hasan et al., "Modern drying techniques in fruits and vegetables to overcome postharvest losses: A review," J. Food Process. Preserv., vol. 43, no. 12, pp. 1-15, (2019), doi: 10.1111/jfpp. 14280 .

[11] B. Ramírez-Pulido, C. Bas-Bellver, N. Betoret, C. Barrera, and L. Seguí, "Valorization of Vegetable Fresh-Processing Residues as Functional Powdered Ingredients. A Review on the Potential Impact of Pretreatments and Drying Methods on Bioactive Compounds and Their Bioaccessibility," Front. Sustain. Food Syst., vol. 5, no. April, (2021), doi: 10.3389/fsufs.2021.654313.

[12] M. C. Karam, J. Petit, D. Zimmer, E. Baudelaire Djantou, and J. Scher, "Effects of drying and grinding in production of fruit and vegetable powders: A review," J. Food Eng., vol. 188, pp. 32-49, (2016), doi: 10.1016/j.jfoodeng.2016.05.001.

[13] L. Van 'T Hag, J. Danthe, S. Handschin, G. P. Mutuli, D. Mbuge, and R. Mezzenga, "Drying of African leafy vegetables for their effective preservation: The difference in moisture sorption isotherms explained by their microstructure," Food Funct., vol. 11, no. 1, pp. 955-964, (2020), doi: 10.1039/c9fo01175g.
[14] N. Amir, M. Efendy, Y. J. Yoo, and M. Gozan, "Improved Salt Quality and Reduced Energy Consumption via Hot Air Drying," Int. J. Technol., vol. 12, no. April, pp. 592-601, (2021), doi: 10.14716/ijtech.v12i3.4853.

[15] F. Cheng, X. Zhou, and Y. Liu, "Methods for Improvement of the Thermal Efficiency during Spray Drying," E3S Web Conf., vol. 53, pp. 46, (2018), doi: 10.1051/e3sconf/20185301031.

[16] A. E. Stępień, J. Gorzelany, N. Matłok, K. Lech, and A. Figiel, "The effect of drying methods on the energy consumption, bioactive potential and colour of dried leaves of Pink Rock Rose (Cistus creticus)," J. Food Sci. Technol., vol. 56, no. 5, pp. 2386-2394, (2019), doi: 10.1007/s13197019-03656-2.

[17] E. Delgado-Plaza, M. Quilambaqui, J. PeraltaJaramillo, H. Apolo, and B. Velázquez-Martí, "Estimation of the energy consumption of the rice and corn drying process in the equatorial zone," Appl. Sci., vol. 10, no. 21, pp. 1-21, (2020), doi: 10.3390/app10217497.

[18] C. Kapseu, D. N. Bup, C. Tchiegang, C. F. Abi, F. Broto, and M. Parmentier, "Effect of particle size and drying temperature on drying rate and oil extracted yields of Buccholzia coriacea (MVAN) and Butyrospermum parkii ENGL," International Journal of Food Science and Technology, vol. 42, no. 5. pp. 573-578, (2007), doi: $10.1111 / \mathrm{j} .1365-2621.2006 .01277 . x$.

[19] S. Pusat, M. T. Akkoyunlu, H. H. Erdem, and I. Teke, "Effects of bed height and particle size on drying of a Turkish lignite," Int. J. Coal Prep. Util., vol. 35, no. 4, pp. 196-205, (2015), doi: 10.1080/19392699.2015.1009051.

[20] Z. Darmawan, A. Altway, and Susianto, "Modeling and Simulation of Salt Drying Using Rotary Dryer," Adv. Sci. Lett., vol. 23, no. 6, pp. 5653-5656, (2017), doi: https://doi.org/10.1166/asl.2017.8793. 